\title{
Septicemia estafilocócica en el niño. Análisis clínico de 11 casos. Hospital Regional de Valdivia
}

\author{
Drs. L. Escobar Orellana, * R. Burgos Laxague, ** J. Berger Venegas* y J. Anzieta Villalobos.**
}

\begin{abstract}
From January 1976 to September 1980, eleven patients with Stuphilox-octal Septicdtmia were treated in the Infectious diseases unit at the Pediatric Service of Valdivia s Regional Hospital.

The diagnosis was conlimed by bacterinlogves shudies in all of them.

The incidence was greater in patients over two years old, with a slighter frecuency in males.

In our experiencie the predisposing factors such as nutritional and inmunulogic conditions were not found to play an important role,

The most affected tissues were the lungs and the osteounticular systems. The follow up showed recovery in ten patients, six of them with secuelae and only one died.
\end{abstract}

La Septicemia Estafilocócica constituye una de las expeniencias clinicas de mayor gravedad dentro de las infecciones provocadas por el estafilococo aureus en el niño; la gravedad del cuadro clinico y la posibilidad de múltiples complicaciones derivadas de la localización del germen en diversos parénquimas deterninan la urgencia de

*Becario Servicio de Pediatria. Hospital Fegional de Valdivia. * Instituto de Pediatría, Facultad de Medicina, Universidad Austral de Chile. establecer un diagnóstico y tratamiento precoz. ${ }^{1.4,}$ 5. 11,12

El propósito de nuestro estudio es analizar la experiencia clínica en el curso de los últimos 4 años.

\section{MATERIAL Y METODOS}

Entre los meses de enero de 1976 a septiembre de 1980, ingresaron a la Unidad de Infecciosos del Servicio de Pediatría, Hospital Regional de Valdivia, 13 niños con diagnóstico de Septicemia Es- 
tafilocócica; seleccionándose 11 casos que tenían confirmación bacteriológica.

El diagnóstico se fundanentó en hallazgos clínicos, de laboratorio y respuesta a terapia especílica. El estudio bacteriológico se efectuó en Hemocultivos, Líquido Céfalo Raquídeo, Líquido Pericárdico, Articular, Mielocultivos y Focos Supurados.

Se analiza la distribución por edad, sexo, estado nutritivo, procedencia, puerta de entrada, síntomas y signos más relevantes y estudio bacteriológico.

\section{RESULTADOS}

Las edades de nuestros pacientes oscilaron entre 2 meses y 14 años, siendo 7 de ellos $(63,6 \%)$ del sexo masculino. La mayor incidencia de septicemia estafilocócica $(81,8 \%)$ se encontró en los mayores de dos años distribuidos en 3 pre-escolares, 3 escolares y 3 adolescentes, todos ellos eutróficos; detectándose desnutrición calórico-proteica grado II y III en 2 lactantes, respectivamente (tabla y gráfico 1 ).

Tabla 1

Distribución por edad, sexo y estado nutritivo en 11 casos de septicemia estafilocócica. Hospital Regional Vaidivia. Servicio Pediatria (1976-1980)

\begin{tabular}{|c|c|c|c|c|c|c|c|c|c|c|}
\hline \multirow{3}{*}{ EDAD } & \multirow{3}{*}{$\mathrm{N} 9$} & \multirow{3}{*}{$\%$} & \multicolumn{4}{|c|}{$S E X 0$} & \multirow{2}{*}{\multicolumn{2}{|c|}{$\begin{array}{l}\text { ESTADO } \\
\text { EUTROFIA }\end{array}$}} & \multirow{2}{*}{\multicolumn{2}{|c|}{$\begin{array}{l}\text { NUIRITIVO } \\
\text { DISTROFIA }\end{array}$}} \\
\hline & & & \multicolumn{2}{|c|}{$\mathbf{M}$} & \multicolumn{2}{|c|}{$F$} & & & & \\
\hline & & & N2 & $\%$ & $\mathrm{~N} \underline{\mathrm{o}}$ & $\%$ & № & $\%$ & № & $\%$ \\
\hline 1-11 meses & 1 & 9.09 & 1 & 9. 09 & & & & & 1 & 9.09 \\
\hline $12-23$ meses & 1 & 9.09 & I & 9.09 & & & & & 1 & 9.09 \\
\hline 2-5 aగ̄os & 3 & 27.27 & 2 & $18 \cdot 18$ & 1 & 9.09 & 3 & 27.27 & & \\
\hline 6-11 ahos & 3 & 27.27 & - & - & 3 & 27.27 & 3 & 27.27 & & \\
\hline $12-15$ oñas & 3 & 27.27 & 3 & 27.27 & & & 3 & 27.27 & & \\
\hline TOTAL & II & 100.0 & 7 & 63.63 & 4 & 36.36 & 9 & B1.B! & 2 & 18.18 \\
\hline
\end{tabular}

\section{Gráfico 1}

Distribución por edad, sexo y estado nutritivo en 11 casos de septicemia estafilocócica. Hospital Regional Valdivia. Servicio Pediatría. (1976-1980)

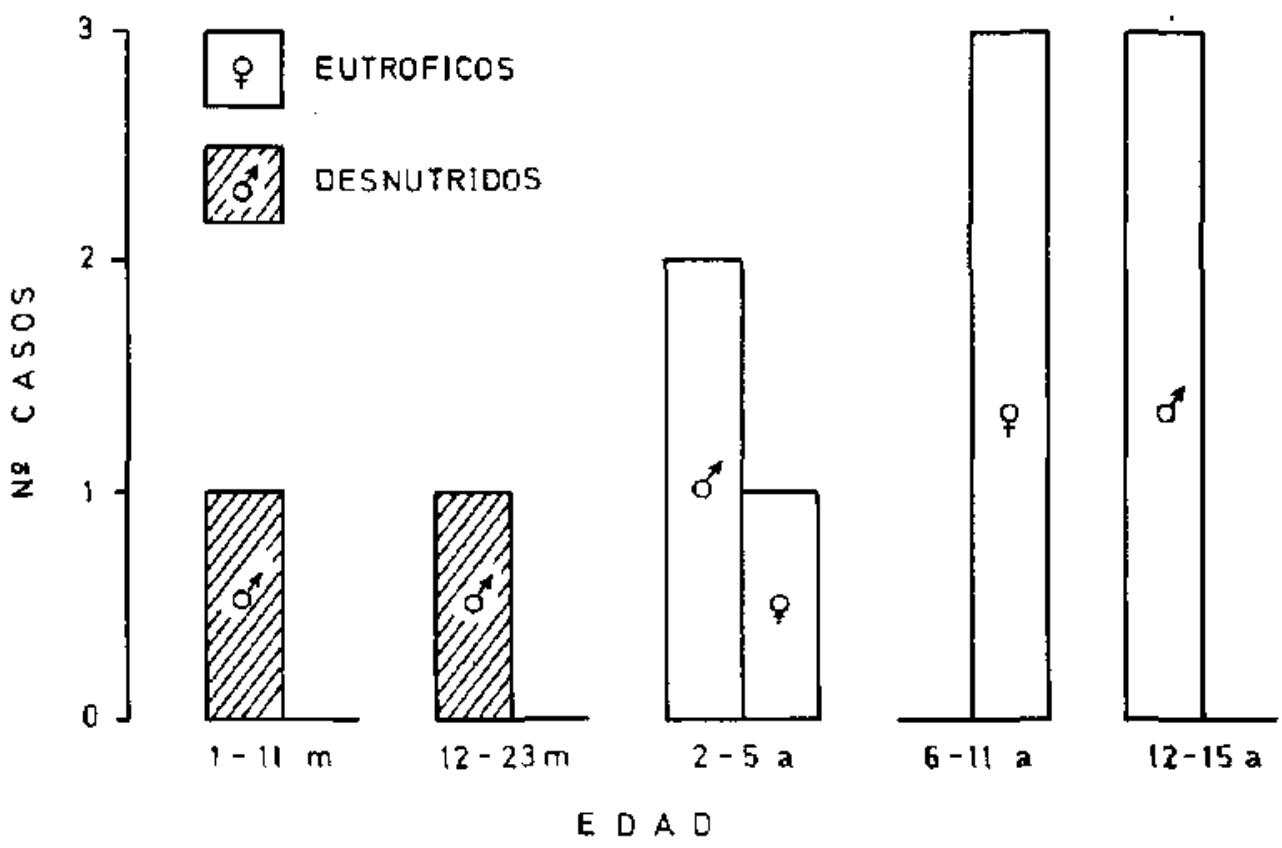


En relación a la procedencia, $72.7 \%{ }^{8}$ tueron derivados de Hospitales Periféricos entre los cuales destacan: La Unión, Máfil, Paillaco, Hío Bueno, Panguipulli y Castro. 7 de ellos eran de zonas rurales; es importante destacar la diferencia significativa que existe en promedio de días con respecto a la primera consulta, siendo de 10.6 días para los niños de zonas rurales y 3.75 días para los de zona urbana.

En la tabla 2 podemos apreciar que la puerta de entrada fue en su mayor parte lesiones de piel $(63.6 \%)$ destacando entre ellas: abscesos, piodermitis, heridas, quemaduras, escara y hematoma infectados. En dos casos, 18.1\%, se originó a partir de un foco pulmonar prinario, $y$ en el mismo porcentaje no se encontró puerta de entrada.

Table 2

Puerta de entrada en 11 nin̄os con septicemia estafilocócica. Servicio Pediatria, Hospital Regional Valdivia. (1976-1980)

\begin{tabular}{|c|c|c|c|c|}
\hline \multirow[b]{2}{*}{ 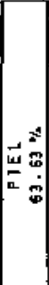 } & & $N * \cos O S$ & $\begin{array}{c}\text { ESTAFILOCDCD } \\
\text { AUFEUS } \\
\text { CULTIYO } 1+1\end{array}$ & $\%$ \\
\hline & $\begin{array}{l}\text { ABCESO CLERO CAEELLUDO } \\
\text { OUEMADURA INFECIADA } \\
\text { HEMATOMA IMFECTADO } \\
\text { HERIOA PUHZMHTE PIE } \\
\text { FLEGMON TOBILLO } \\
\text { ESCARA OLUTEA } \\
\text { PUSTULAS PIEL }\end{array}$ & $\begin{array}{l}1 \\
1 \\
1 \\
1 \\
1 \\
1 \\
1\end{array}$ & $\begin{array}{l}1 \cdot 1 \\
1+1 \\
1+\vdots \\
1-\vdots \\
1 \cdot 1 \\
1-: \\
1-:\end{array}$ & 63,63 \\
\hline 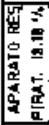 & $\begin{array}{l}\text { BAONCONELAMOHLA } \\
\text { EILAIERAL }\end{array}$ & 2 & & $18 \cdot 18$ \\
\hline & DESCONDCIDA & 2 & & 18.18 \\
\hline & TOIAL & 11 & & no.0 \\
\hline
\end{tabular}

Gráfico 2

Distribución en onden de frecuencia de síntomas $y$ signos en 11 casos de septicemia estafilocócica. Hospital Regional Valdivia. (1976-1980)

SINIOMAS Y SIGWOS

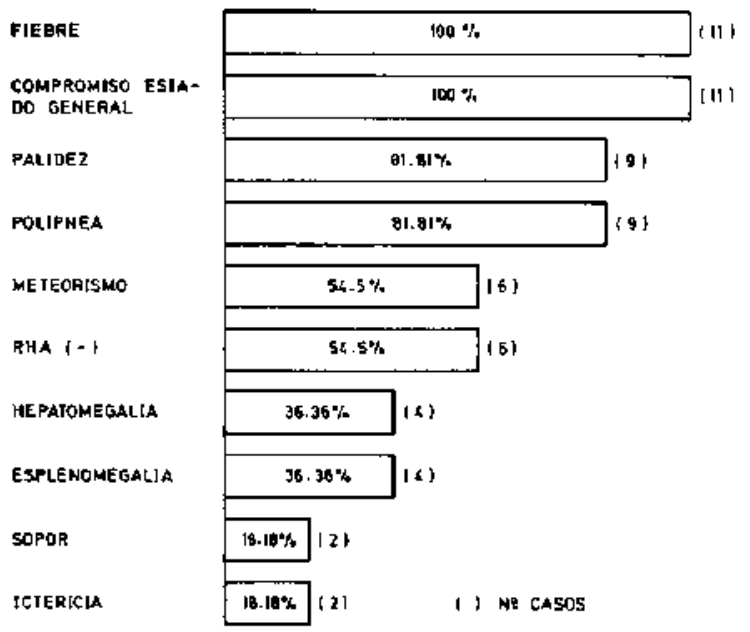

Entre los síntomas y signos de ingreso (gráfico 2) destaca en todos los casos, fiebre, compromiso del estado general y en menor porcentaje palidez y polipnea, presentando sólo 4 casos Hepatoesplenomegalia, siendo más rara las manitestaciones cutaneas e ictericia.

El síndrome febril tuvo una duración promedio de 15.2 dias, oscilando entre 9 y 24 dias. siendo más prolongada en aquellos casos en que persistían focos supurados drenados parcialmente.

Los parénquimas más afectados (gráfico 3), fueron el aparato respiratorio $(81.8 \%)$ y Osteoarticular (54.5\%); correspondiendo el compromiso pulmonar en todos los casos a focos de condensación bilaterales de extensión variable, traducidos radiológicamente por imágenes macronodulares irregulares distribuidas en ambos campos pulmonares (Fig. 1). El compromiso pleural se manifestó en 4 casos correspondiendo a derrames de pequeña a mediana cuantia que no requinieron drenaje quirúrgico. Neumatocele se observó sólo en 4 cussos.

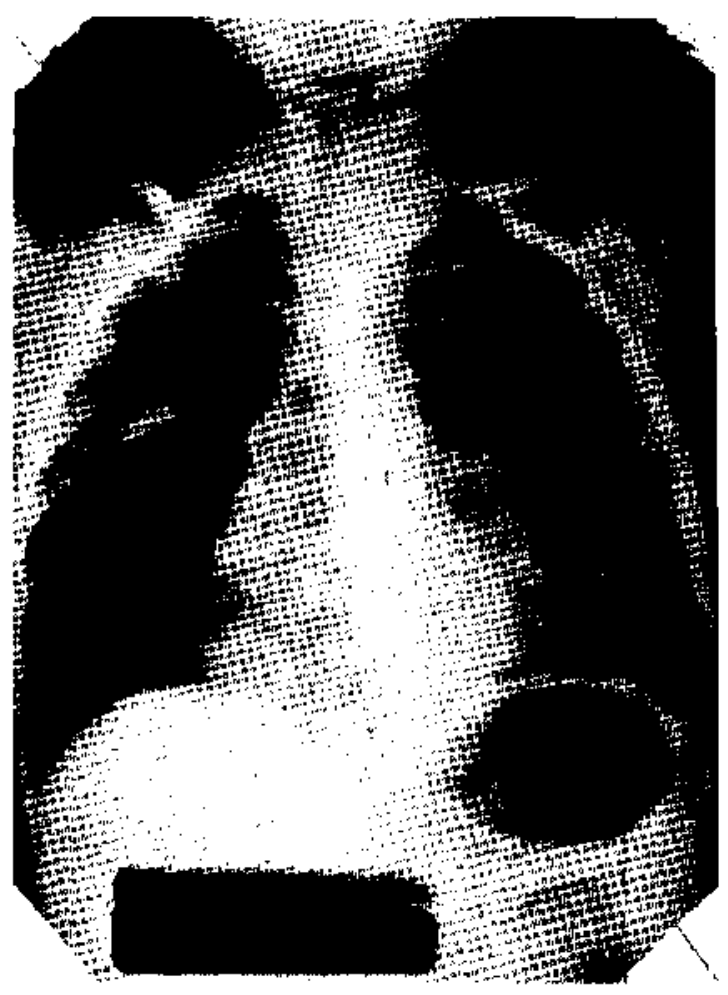

Figura 1. Radiografia de tórax. Silueta cardíaca de tamario normal, imágenes nuacronodulares de diversos tamaños en ambos campos pulmonares; uscocíados a proceso condensante de segmentu basal posterior de lobbulo inferior izquierdo. Compatible con proceso nelimónico condensante asociado a focos sépticos metastásicos. 


\section{Gráfico 3}

Compromiso secundario de diferentes parénquimas en 11 niños con septicemia estafilocócica. (1976-1980)

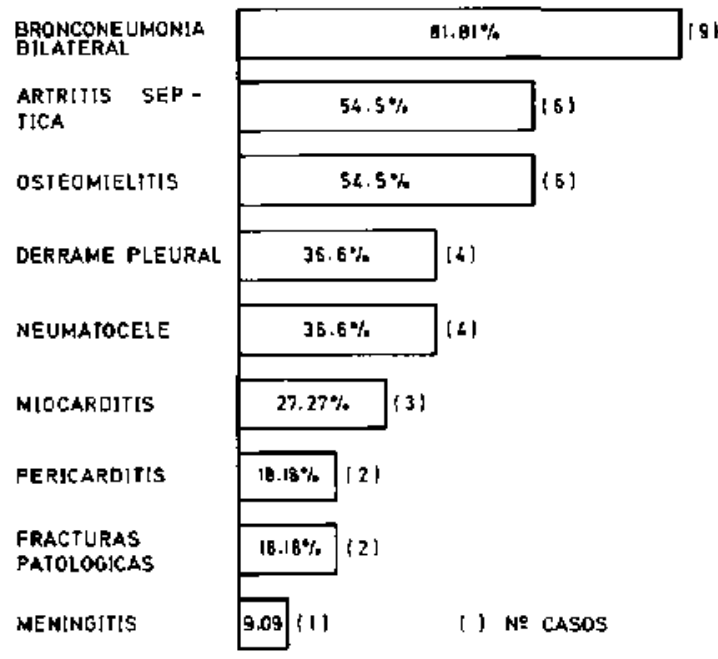

El compromiso Osteoarticular se encontró en 6 casos correspondiendo a Artritis Séptica, Osteomielitis, en todos ellos, presentando dos pacientes fracturas patológicus. (Fig. 2).

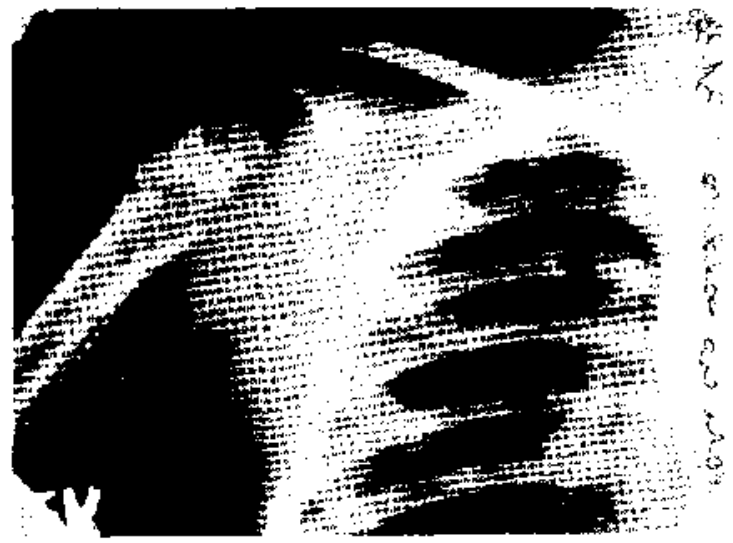

Figura 2. Radiografia hombro derecho. Significativo aumentr de partes blandas, con franca reacción perióstiea y dismirución de la densidad osea radiológica. Fractura patológica del extrenos proximal de la diafasis humeral ${ }_{i}$ alteraciomes compatibles con osteomielitís localizada en proceso agudo.

Alteraciones cardiacas fueron evidentes en 3 casos, 2 de los cuales presentaron pericarditis y miocarditis demostradas por cuadro clínico, estudio radiológico y electrocardiograma, requiriendo uno de ellos drenaje a través de Pericardiostomia; en tanto que el otro sólo Pericardiocéntesis evacuadora, evolucionando ambos en forma satisfactoria (Fig. 3).

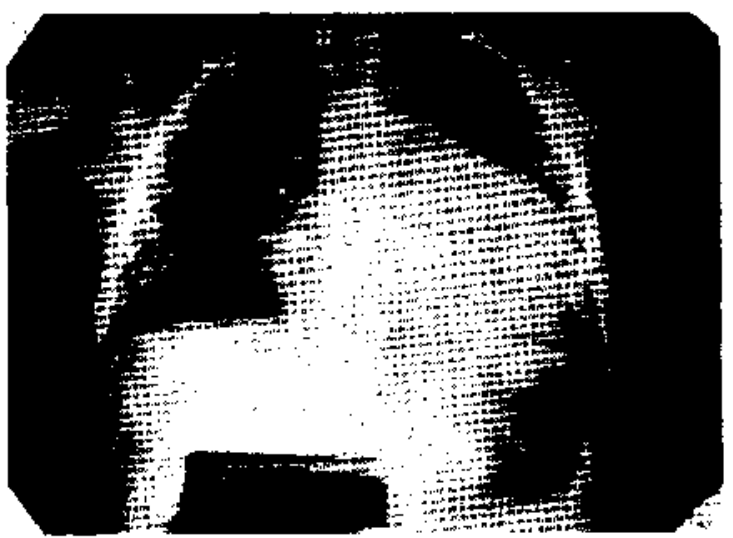

Figura 3. Radiografia de tórax. Aumento global de silueta cardiacia compatible con ocupación pericárdica y cardiaco. Intiltrato peribronequial paracardiaco derecho.

Síndrome Meuíngeo se evidenció en dos casos comprobándose bacteriologicamente en L.C.R de uno cle ellos. En la tabla 3 se detalla el estudio bacteriológico de los 11 casos obteniéndose cultivos positivos a Estafilococo aureus, coagulasa positivo en 9 hemocultivos, 6 lesiones de piel, 2 de lícpuido articular, 1 de líquido pericárdico, 1 de líquido cetalorraquídeo y l de mielocultivo; cabe haces notar que en el caso N." 2 aurque los hemocultivos resultaron negativos se pudo aislar el germen de piel, pericardio y L.C.R., lo cual nos permite confimar el diagnóstico; lo mismo en el caso N." 7 en que se obhuvo cultivo positivo sólo de licquido articular, siendo el cuadro clíríco compatible, con míltiples localizaciones: hematoma infectado, artritis séptica de tobillo, bronconeumonia bilateral, rush cutáneo, ictericia y gran compromiso del estado general.

\section{Tabla 3}

Distribución del estudio bacteriológico de 11 niños cun septicenia estafilocócica. Servicio Pediatría. Hospital Regional Vuldivia. (1976-1980)

\begin{tabular}{|c|c|c|c|c|c|c|}
\hline CASOS & $\begin{array}{l}\text { HEMOCUL- } \\
\text { I!YO }\end{array}$ & $\begin{array}{c}\text { PUS } \\
\text { ARTIC ULARR }\end{array}$ & PIEL & $\begin{array}{l}\text { PERI - } \\
\text { CARDIO }\end{array}$ & L.C.R. & $\begin{array}{l}\text { MIELO- } \\
\text { CULTSYO }\end{array}$ \\
\hline 1 & $\cdots$ & \multirow{11}{*}{$\begin{array}{l}1.1 \\
1+1\end{array}$} & & \multirow{11}{*}[+]{} & \multirow{9}{*}{$t+1$} & \multirow{11}{*}{-1} \\
\hline$\lambda$ & & & $1+1$ & & & \\
\hline 1 & $1+91 \cdot 11-1$ & & $1+1$ & & & \\
\hline 2 & $(t-1)+1(t+)$ & & & & & \\
\hline 5 & $t+t+t+b$ & & & & & \\
\hline t & {$[(+\forall-3]-1)$} & & & & & \\
\hline 7 & & & & & & \\
\hline b & $|+|) \mid-H=\}$ & & $1+1$ & & & \\
\hline 9 & $x+1(-)<-1$ & & $1+1$ & & & \\
\hline 10 & $(x+3)-3 x-1$ & & $1+1$ & & $1-1$ & \\
\hline " & $(1+1)-15-1$ & & $1+1$ & & $1-1$ & \\
\hline IOTAL, & $81.01 \%$ & $118.1 \%$ & $165.5 \%$ & $\mid 9.00 \%$ & $9.09 \%$ & $9.09 \%$ \\
\hline
\end{tabular}


De los examenes practicados al ingreso en 8 casos destacaba leucocitosis, desviación a izquierda y V.E.S. sobre $50 \mathrm{~mm}$ en la primera hora, cuyo control sirvió como parámetro de recuperación del cuadro.

En nuestra serie falleció un solo niño y correspondió a um lactante menor que ingresó en malas condiciones generales, enviado de un hospital periférico con múltiples localizaciones sépticas $y$ un Hemocultivo positivo a Estafilococo atureus.

\section{COMENTARIO}

Durante el periodo que corresponde al estudio ingresaron a la Unidad de Infecciosos 1.140 niños, de los cuales 11 correspondieron a Septicemia Estafìlocócica, lo que nos da una incidencia de $0.96 \%$.

Standford T. Shulman' presenta entre los años 1972 y 1975, 9 niños previamente sanos con edades entre 8 y 15 años con manifestaciones severas de Septicemia provocada por Estafilococo aureus, llamando la atención en ese estudio la ausencia de factores anergizantes que pudieran tener un rol predisponente en está afección, hecho que tambien pudimos apreciar en nuestro estudio en que se encontró solamente un caso correspondiente a un lactante en tratamiento con Inmunosupresores por enfermedad de Letterer Siwe.

En la literatura nacional las publicaciones son escasas, destacando un estudio realizado en el Hospital Guillenmo Grant Benavente de Concepción, ${ }^{2}$ en que se revisa pericarditis purulenta en una experiencia de 10 años, encontrándose asociada a septicopiohemia en $91 \%$ de los casos, destacando que la puerta de entrada más frecuente fue piel, lo cual concuerda con nuestro estudio en que se encontró este antecedente en un $63.6 \%$.

Es probable que las diversas modalidades clínicas observadas sean la resultante de la interacción entre la respuesta inmunitaria del individua y el mayor o menor grado de virulencia del germen, de modo que pueden observarse formas agudas severas en las que predomina inicialmente el cuadro tóxico y otras en las cuales la sintomatología es comandada fundamentalmente por la presencia de un foco supurado (artritis, bronconeumonía, etc.) sobre el cuadro toxinfeccioso general. $4,5,7,11,12$

La edad también es un factor importante, siendo en el menor de dos años un problema extraordinariamente complejo, ya que se pueden observar fornas subclínicas y otras con compromiso acentuado de los diversos parémquintats, correspondiendo estat últina modalidad a la esolución de uno de nuestros pacientes que talleció a las pocas horas de haber ingresado. $1,5,8,11$

En los niños mayores de 2 años se ha descritn como un cuadro de iniciación rápida que se caracteriza por marcado compromiso del estado general, fiebre alta, padidez, sintomas respiratorios, compromiso osteoarticular, findanentalmente artralgias o aumerito de volumen periarticular, lo cual en mestra experiencia tie un índice orientador en el momento del ingreso; aun cuando la traducción radiológica no fue evidente hasta por lo menos una semana de injeiados los síntomess clínicos. ${ }^{6}$

Las localizaciones clínicas más evidentes fueron la pulmonar y osteoarticular, siendo las articulaciones mas afectadas: tobillos, rodillas $y$ caderas. Aquellos casos cuya evolución fue tórpida con fiebre prolongada en general tenian localizaciones óseas muiltiples que fỉnalmente condujeron a osteomielitis crónicas y en menor porcentaje a fracturas patológicas.

El compromiso pulmonar correspondió al Bronconeumonía bilateral en $81.8 \%$ de los casos, con múltiples focos sépticos metastísicos que se evidenciaron radiológicamente como imágenes macronodulares irregulares bilaterales, Ilamando la atención que el compromiso pleural sólo se presentó en $\mathbf{5}$ casos y fue de discreta a mediana cuantía, a diferencia de lo que se describe en los casos de Pleuroneunonúa Estafilocócica primarja en que por lo general se instala Pioneumotórax en pocas horas y requiere drenaje quinúrgico de inmediato, $5,6,11$

Entre las localizaciotnes secundarias el conpromiso cardiaco fut menus trecuente, detectíndose miocarditis en 3 casos, de los cuales dos presentaron además Pericarditis purulenta.

Afortumadamente la Iocalización en el Sistema Nervioso Central en nuestra experiencia tie menos frecuente (dos casos comprobándose bacteriológicamente sólo en uno de ellos).

De los estudios bacteriológicos efectuados el Estafilococo auteus tive aislado en todos los casos, siendo sensibles todos ellos a Cloxacilina con sólo 2 cepas sensibles a Penicilina Sódica.

Los pacientes se presentaron a través del año sin predominio estacional. 
En base a nuestra experiencia se comprueba una vez más que el tratamiento debe ser precoz $\mathrm{e}$ intensivo, sobre la base de antibioticos especificos, drenajes quinúrgicos de colecciones supuradas y durante un período lo suficientemente prolongado para prevenir reagudizaciones. En nuestro estudio el tratamiento se mantuvo en promedio 7 semanas ${ }^{5}$ y el promedio de hospitalización fue de 44.6 días ( 6 semanas).

\section{RESUMEN}

Análisis clínico de 11 niños ingresados a la Unidad de Infecciosos, Servicio de Pediatria, Hospital Regional de Valdivia, entre los meses de enero de 1976 y septiembre de 1980 , con diagnóstico de Septicemia Estafilocócica confirmado bacteriológicamente en todos los casos.

Destaca mayor incidencia en niños sobre 2 años de edad, eutroficos, ligero predominio en varones, y como puerta de entrada principal, lesiones de piel.

Los parénquimas más afectados fueron el pulmonar y osteoarticular.

De los casos analizados hubo recuperación en
10 , quedando 6 de ellos con secuelas ostecarticulares y un paciente que fallece.

\section{REFERENCIAS}

'Standford, T,; Shulman, M.D., y Elia, M. Ayouh, M.D. "Seven Stafilococcal Sepsis in Adolescents". Department of Pediatries, Division of Infectious disease and Inmtrology, University of Florida, Gainesville. Pediatrics Vol. 58, N.0 1, July 1976. 59-65.

${ }^{2}$ Pacheco, V.; Cerezo, S.; Venegas, G. Pericarditis Purulenta en ta Infancia. Rev. Chil. Pediatria, Vol. 46, septiembre-diciem. bre, 1975.

3 Nomut, J; Roger, P.; Compusano, A. Infecciones Estafilococicas en el Niño. Pediatró, Santiago, Chile, Vol.21: $304,1978$.

${ }^{4}$ Melcin Ramsay, A.; Funuld, T.; Emond. D. Enfermedades Infecriosas. Editorial Cientrlico Médica 1970, 303-314.

5 Meneghello, $J$. Tratado de Pediatria, 2," Ed., 1520-1530, 1978.

${ }^{6}$ Edeiken Hodes. Diagnósticos radiológicos de las enfermeda des de los huesos. 668-677, 1977.

${ }^{7}$ Pobent Fuerst. Frobisher and Fuert's Microbiology in Health and disease. Universidad de Texas, 1978.

*William, E., Feidman, M. D. Etiologia Bacteriana y Mortalidad de la Pericarditis purulenta en pacientes pediátricns. Am. Jour. Disease Chidiren 133; junio 1979.

9 Youmans, Patterson, Sommers. The Biologic and clinical basis of infections diseases; $596-609,1975$.

${ }^{10}$ Benjumin M. Kegan. Terapéutica antimicrobiana. 204-213; 1978.

II Nelson, Vaughan, McKoy. Infecciones Estafilocicicas. Trat: do de Pediatria, 6. Ed. T. II: $939,1974$.

12 Hamison, Tratado de Medicina Interna, VI Ed. Pag, $1867-870$, 1973. 